\title{
Aspirin enhances doxorubicin-induced apoptosis and reduces tumor growth in human hepatocellular carcinoma cells in vitro and in vivo
}

\author{
MOHAMMAD AKBAR HOSSAIN ${ }^{1}$, DONG HWAN KIM ${ }^{1}$, JUNG YOON JANG ${ }^{1}$, YONG JUNG KANG ${ }^{1}$, \\ JEONG-HYUN YOON ${ }^{1}$, JEON-OK MOON ${ }^{1}$, HAE YOUNG CHUNG ${ }^{1}$, GI-YOUNG KIM ${ }^{2}$, \\ YUNG HYUN CHOI ${ }^{3}$, BRYAN L. COPPLE ${ }^{4}$ and NAM DEUK KIM ${ }^{1}$
}

\begin{abstract}
${ }^{1}$ Division of Pharmacy, College of Pharmacy, Molecular Inflammation Research Center for Aging Intervention (MRCA), Pusan National University, Busan 609-735; ${ }^{2}$ Faculty of Applied Marine Science, Cheju National University, Jeju 690-756; ${ }^{3}$ Department of Biomaterial Control (BK21 Program), Dongeui University Graduate School, Busan 614-052, Republic of Korea; ${ }^{4}$ Department of Pharmacology and Toxicology, Michigan State University, East Lansing, MI 48824, USA
\end{abstract}

Received October 13, 2011; Accepted December 20, 2011

DOI: $10.3892 /$ ijo.2012.1359

\begin{abstract}
Combined therapy with multiple drugs is a common practice in the treatment of cancer, which can achieve better therapeutic effects than a single drug, and can reduce the side effects as well as drug resistance. This study aimed to determine whether aspirin (ASA) shows synergism with doxorubicin (DOX) in HepG2 human hepatocellular carcinoma cells in vitro and in a HepG2 cell xenograft model in BALB/c nude mice. When treated in combination, DOX $(0.25 \mathrm{nmol} /$ $\mathrm{ml})$ and ASA $(5 \mu \mathrm{mol} / \mathrm{ml})$ produced strong synergy in growth inhibition, cell cycle arrest and importantly, apoptosis in vitro in comparison to single treatments. Moreover, ASA (100 mg/ $\mathrm{kg} /$ day orally) and DOX (1.2 mg/kg biweekly ip) induced synergistic antitumor activity in the HepG2 cell xenograft model in nude mice. Therefore, the combination of ASA and DOX could be used as a novel combination regimen which provides a strong anticancer synergy in the treatment of hepatocellular carcinoma.
\end{abstract}

\section{Introduction}

Hepatocellular carcinoma (HCC) is the fifth most common cancer worldwide and more than half a million new cases occur annually. In some areas of Southeast Asia and the Africa, HCC ranks as the first cause of death from cancer. The incidence of $\mathrm{HCC}$ is also increasing in Europe and in the United States (1).

Correspondence to: Dr Nam Deuk Kim, Department of Pharmacy, College of Pharmacy, Pusan National University, Busan 609-735, Republic of Korea

E-mail: nadkim@pusan.ac.kr

Key words: aspirin, doxorubicin, hepatocellular carcinoma, apoptosis, xenograft model
Chemotherapy is one of the common strategies in the treatment of inoperable HCC treatment. Doxorubicin (DOX) has been widely used as the anticancer drug in the various kinds of malignancies including HCC (2). However, the objective response rate is $<20 \%$ and the median survival is only 4 months when DOX is used as a single agent (3). In addition, it causes serious side effects, in particular cumulative, dose-related myocardial toxicity limiting its use. Thus it is necessary to seek a new combination therapy which can enhance anticancer effectiveness. Currently, nearly all successful cancer chemotherapy regimens adopt a strategy of combination of multiple agents given simultaneously, thereby achieving better therapeutic efficacy and minimizing side effects.

Acetylsalicylic acid (ASA) is a non-steroidal anti-inflammatory drug (NSAID) with many pharmacological properties, such as anti-inflammatory, anti-pyretic, and analgesic. Recent studies have shown that the long-term administration of ASA in humans leads to protection against the development of colorectal cancer as well as malignancies in other tissues $(4,5)$. Especially, use of $300 \mathrm{mg}$ or more of ASA a day for about 5 years reduces the short-term risk of recurrent colorectal adenomas in patients with a history of adenomas or cancer (6). The anticancer activity of ASA is thought to be linked to their ability to inhibit cell proliferation and to induce apoptosis (7). We hypothesized that combination of ASA and DOX might be effective in the treatment of HCC since ASA has been reported to show anticancer effect on HCC $(8,9)$. Therefore, the present study was designed to investigate whether the cytotoxic properties of ASA and DOX were synergistic when used together in HepG2, human HCC cell line, in vitro and HepG2 cell xenograft model in BALB/c nude mice in vivo.

\section{Materials and methods}

Chemicals. ASA and DOX were purchased from SigmaAldrich Co. (St. Louis, MO). ASA was freshly prepared before each experiment and solubilized as described elsewhere (10) and DOX was dissolved in phosphate-buffered saline (PBS) 
for in vitro experiments. All other chemicals and reagents were from standard commercial sources and of the highest purity.

Cell culture and cell viability assay. HepG2 (wild-type p53, $\mathrm{Rb}$-positive, Ras-mutated and HBV-negative) cells, the human hepatocellular carcinoma cell line, were purchased from the American Type Culture Collection (Manassas, VA), and maintained at $37^{\circ} \mathrm{C}$ in a humidified condition of $95 \%$ air and $5 \% \mathrm{CO}_{2}$ in DMEM (Gibco-BRL, Gaithersburg, MD) supplemented with $10 \%$ heat inactivated fetal bovine serum (FBS), $2 \mathrm{mM}$ glutamine, $100 \mathrm{U} / \mathrm{ml}$ penicillin, and $100 \mu \mathrm{g} / \mathrm{ml}$ streptomycin. Cell proliferation was assessed using MTT [3-(4,5-dimethylthiazol2-yl)-2,5-diphenyltetrazoliumbromide, Sigma-Aldrich Co.] assay, as described before (11), which is based on the conversion of MTT to MTT-formazan by mitochondrial enzymes. Since the same number of cells was aliquoted into each well initially, decreased optical density in wells containing treated cells reflects cellular death and/or decrease in the rate of proliferation. To distinguish between these two possibilities, we employed an additional cytotoxicity assay which detects cell death by lack of trypan blue exclusion. Cell death was determined by trypan blue exclusion. Cells were incubated with $0.2 \%$ trypan blue for 2-5 min, and the percentage of dead cells (those which did not exclude the dye) was determined microscopically.

DNA fragmentation assay. DNA fragmentation was performed as described previously (12). Briefly, after treatment with ASA and/or DOX, cells were rinsed twice in cold PBS and resuspended in lysis buffer [5 $\mathrm{mM}$ Tris- $\mathrm{HCl}(\mathrm{pH} 7.5), 5 \mathrm{mM}$ ethylene diamine tetraacetic acid and $0.5 \%$ Triton X-100] at $4^{\circ} \mathrm{C}$ for $30 \mathrm{~min}$. After centrifugation at $27,000 \mathrm{x} \mathrm{g}$ for $15 \mathrm{~min}$, the supernatant was treated with RNase, followed by proteinase $\mathrm{K}$ digestion, phenol/chloroform/isoamyl alcohol (25:24:1, v/v/v) extraction and isopropanol precipitation. DNA was separated through a $1.5 \%$ agarose gel, and stained with $0.1 \mu \mathrm{g} / \mathrm{ml}$ ethidium bromide (EtBr, Sigma-Aldrich Co.), and was visualized by ultraviolet light source.

Gel electrophoresis and Western blot analysis. The cells were harvested, lysed, and protein concentrations were quantified using the Bio-Rad protein assay (Bio-Rad Lab., Hercules, CA), following the procedure described by the manufacturer. Western blot analysis was performed as described previously (13). Briefly, an equal amount of protein was subjected to electrophoresis on SDS-polyacrylamide gels and transferred to nitrocellulose membranes (Schleicher \& Schuell, Keene, NH) by immunoblotting. Blots were probed with the desired antibodies overnight, incubated with diluted enzyme-linked secondary antibodies and then visualized by the enhanced chemiluminescence (ECL) according to the recommended procedure (Amersham Corp., Arlington Heights, IL). The primary antibodies and peroxidaselabeled goat anti-rabbit and goat anti-mouse immunoglobulins were purchased from Santa Cruz Biotechnology Inc. (Santa Cruz, CA).

Caspase activity assay. Activities of caspase-3, -8 and -9 were determined using the corresponding caspase activity detection kits (R\&D Systems) as described by the manufacturers. Briefly, cells were harvested and cold lysis buffer was added, and then incubated on ice for $10 \mathrm{~min}$ and centrifuge for $1 \mathrm{~min}$ in a microcentrifuge $(10,000 \mathrm{xg})$. The supernatant was transferred to a fresh tube and protein concentration was determined using a standard colorimetric assay (Bio-Rad Laboratories). The protein concentration of each sample was adjusted to $200 \mu \mathrm{g}$ per $50 \mu \mathrm{l}$ of cell lysate using chilled cell lysis buffer. Then added $50 \mu \mathrm{l}$ of $2 \mathrm{X}$ reaction buffer and $5 \mu \mathrm{l}$ substrates of DEVD-pNA (for caspase-3), IETD-pNA (for caspase-8), and LEHD-pNA (for caspase-9), respectively. Samples were incubated at $37^{\circ} \mathrm{C}$ for $2 \mathrm{~h}$ and the enzyme-catalyzed release of pNA was quantified at $405 \mathrm{~nm}$ using a microtiter plate reader. The values of treated samples were normalized to the untreated controls, allowing determination of the fold increase in caspase activity.

Cell cycle analysis. After treatment with ASA and/or DOX, cells were trypsinized, washed with $1 \% \mathrm{BSA}$, and fixed in $95 \%$ ethanol at $-20^{\circ} \mathrm{C}$ overnight. Prior to analysis, cells were again washed with $1 \%$ BSA, suspended in PBS with RNase A $(100 \mu \mathrm{g} /$ $\mathrm{ml}$ ) and incubated at $37^{\circ} \mathrm{C}$ in the dark for $30 \mathrm{~min}$, propidium iodide (PI, Sigma-Aldrich Co.) solution $(10 \mu \mathrm{g} / \mathrm{ml})$ were added before flow cytometry analysis performed on a FACScan flow cytometry system (Becton-Dickinson, San Jose, CA).

In vivo xenograft model. Six-week-old male BALB/c nude mice (obtained from Japan SLC, Inc., Japan) were used for in vivo animal experiments. The animals were housed in constant laboratory conditions of a 12-h light/dark cycle and specific pathogen-free conditions and fed with water and food ad libitum. The animal protocol used in this study has been reviewed and approved by the Pusan National University-Institutional Animal Care and Use Committee (PNU-IACUC, Busan, Korea) on their ethical procedures and scientific care. For xenograft study, mice were inoculated subcutaneously into the right-back with $1 \times 10^{7} \mathrm{HepG} 2$ cells in $200 \mu \mathrm{l}$ PBS and Matrigel (1:1). When average tumor volume reached $200 \mathrm{~mm}^{3}$, mice were randomly assigned to four treatment groups of five mice each: control ( $0.5 \%$ sodium carboxymethyl cellulose by oral gavage and water for injection ip), DOX $(1.2 \mathrm{mg} / \mathrm{kg}$ biweekly ip); low dose scheduled for minimal side effects (14), ASA (100 mg/kg/day by oral gavage), and ASA+DOX (given concurrently on days when both drugs were given). The mice were treated for 3 weeks and the body weight and tumor volume [(major axis) $\mathrm{x}$ (minor axis) $)^{2}$ x 0.5$]$ of each mouse were monitored biweekly up to the end of the experiment (3 weeks). DOX was dissolved in water for injection and ASA was grounded into a fine powder in a mortar and pestle, suspended in $0.5 \%$ sodium carboxymethyl cellulose.

Statistical analysis. The data are presented as means \pm SEM of three independent determinations. ANOVA was conducted to analyze significant differences among the groups. Other statistical analyses were carried out by the Student's t-test. ${ }^{*} \mathrm{p}<0.05$ and ${ }^{* *} \mathrm{p}<0.01$ were considered to be significant. Combination data were analysed using Calcusyn, a Windows software package for dose effect analysis from Biosoft (Cambridge, UK). The program provides combination index (CI) values which are a quantitative measure of drug interaction in terms of an additive (CI 1), synergistic (CI <1) or antagonistic (CI >1) effect for a given endpoint of the assay used, adapted from Chou and Talalay (15). 




Figure 1. ASA enhances DOX-induced cell death of HepG2 cells. The cells were treated with ASA $(5 \mu \mathrm{mol} / \mathrm{ml})$ and/or DOX $(0.25 \mathrm{nmol} / \mathrm{ml})$ for $48 \mathrm{~h}$, and then percentage of cell survival was determined using the MTT assay. Results are expressed as percentage of the control \pm SEM of three separate experiments. Statistical analyses were performed by comparison of averages between groups with ASA+DOX treatment and those DOX or ASA treatment $\left({ }^{*} \mathrm{p}<0.05\right)$.

\section{Results}

ASA synergized with DOX to reduce the viability of Hep 2 cells in vitro. To determine whether ASA shows synergism with DOX in HepG2 cells, cells were treated with or without ASA and/or DOX for $48 \mathrm{~h}$ and were quantified by MTT assay. As shown in Fig. 1A, ASA $(5 \mu \mathrm{mol} / \mathrm{ml})$ or DOX $(0.25 \mathrm{nmol} / \mathrm{ml})$ alone exerted 86 and $69 \%$ viability (i.e., decrease in cell numbers by 14 and $31 \%$ respectively), as compared to control. Of note, combination treatment resulted in $56 \%$ viability, decreasing cell numbers by as much as $44 \%$, with statistical significance (all are $\mathrm{p}<0.05$ ). A further quantitative determination of synergistic effect by the combination treatment of ASA and DOX were carried out through the combination index (CI) method of Chou and Talalay (15). After $48 \mathrm{~h}$ of exposure, DOX inhibited cell viability in a dose-dependent manner, with and without various concentrations of ASA. However, combination treatment of DOX and ASA exhibited the synergistic effect, leading to a shift of the DOX survival curves to the lower left by the incremental doses of ASA (Fig. 2A) and the CI plots (Fig. 2B). Virtually all CI values were significantly $<1$ which indicates the synergy between ASA and $\operatorname{DOX}(15)$.

ASA promotes DOX-induced cell death in vitro. Although flow cytometry analysis of Annexin V and PI double staining is a wellaccepted assay to determine apoptotic cell death, this method is not suitable for cells treated with DOX as it emits a very strong and broad-band fluorescence that interferes with the assay (16). Considering the afore-mentioned problem, we used trypan blue staining instead to quantify cell death caused by ASA, DOX, or the combination. Dead cells take up the dye whereas viable cells do not. The percentage of dead cells was calculated by counting 1,000 cells each time. As shown in Fig. 3A, treatment with a single agent of $5 \mu \mathrm{mol} / \mathrm{ml}$ of ASA or $0.25 \mathrm{nmol} / \mathrm{ml}$ of DOX over 48-h period increased cell death slightly compared with the untreated control whereas the combination of ASA and DOX was more potent, with statistical significance $\left({ }^{*} \mathrm{p}<0.05 ;{ }^{* *} \mathrm{p}<0.01\right)$. Trypan blue staining quantifies all non-viable cells making no distinction of cell death by apoptosis. To clarify this issue, we used the DNA fragmentation method which is highly specific for observing apoptotic cell death, to study synergism between ASA and DOX. Cells were treated for $48 \mathrm{~h}$ with $5 \mu \mathrm{mol} / \mathrm{ml}$ of ASA or $0.25 \mathrm{nmol} / \mathrm{ml}$ of DOX as a single agent, or in combination. The results in Fig. 3B showed that ASA or DOX caused no significant increase in apoptosis and is very similar to control. In contrast, the response to the combination was more robust and it seems that ASA and DOX work cooperatively to commit cells to apoptosis. To investigate the mechanism by which apoptosis was induced by combination of ASA and DOX, we evaluated the expression levels of Bax and Bcl-2 proteins. Combination of ASA and DOX markedly down-regulated $\mathrm{Bcl}-2$ protein expression but did not make an appreciable difference in the Bax expression (Fig. 3C). Consequently an increase in Bax/ Bcl-2 ratio was observed (Fig. 3D). The synergy between ASA and DOX in causing apoptotic cell death was consistently observed across three different assays.

ASA promoted DOX-induced caspase activation. Since caspase-3, -8 and -9 play central roles in the apoptotic cascade, the activities of these three enzymes during the induction of
A

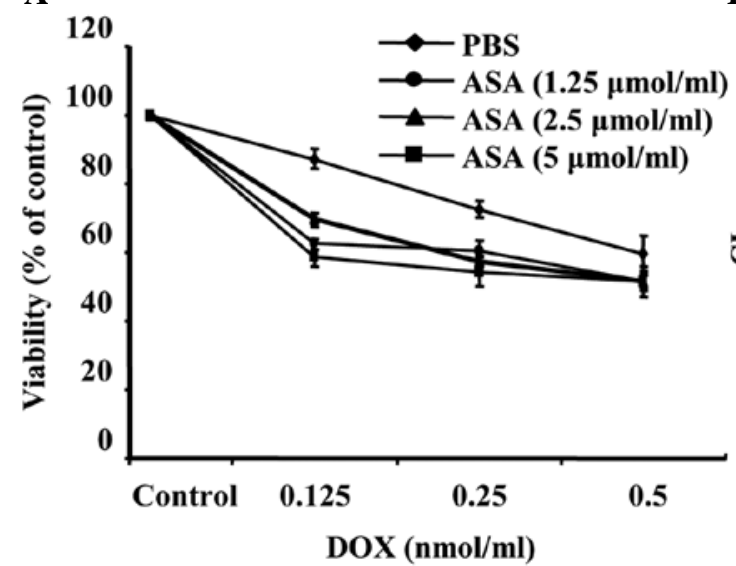

B

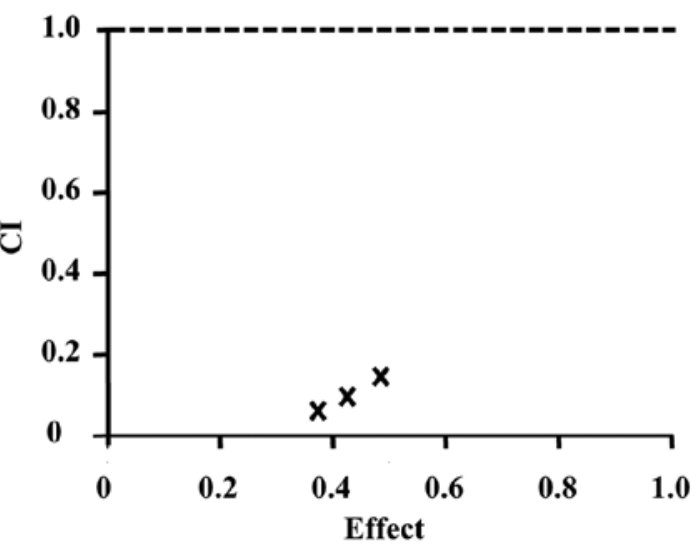

Figure 2. ASA showed synergism with DOX-induced cytotoxicity in HepG2 cells. (A) Cells were treated with DOX (0.125-0.5 nmol/ml) in the presence of PBS (rhombus), $1.25 \mu \mathrm{mol} / \mathrm{ml}$ ASA (circle), $2.5 \mu \mathrm{mol} / \mathrm{ml} \mathrm{ASA} \mathrm{(triangle),} \mathrm{or} 5 \mu \mathrm{mol} / \mathrm{ml}$ ASA (square) for $48 \mathrm{~h}$, then percentage of cell survival was measured by MTT assay. Results are expressed as percentage of the control \pm SEM of three separate experiments. (B) Combination index (CI) plots of ASA+DOX versus the inhibition (fraction affected) of cell survival, where CI $>1,<1$, and 1 indicate antagonism, synergy, and additive effect, respectively. PBS, phosphate-buffered saline. 


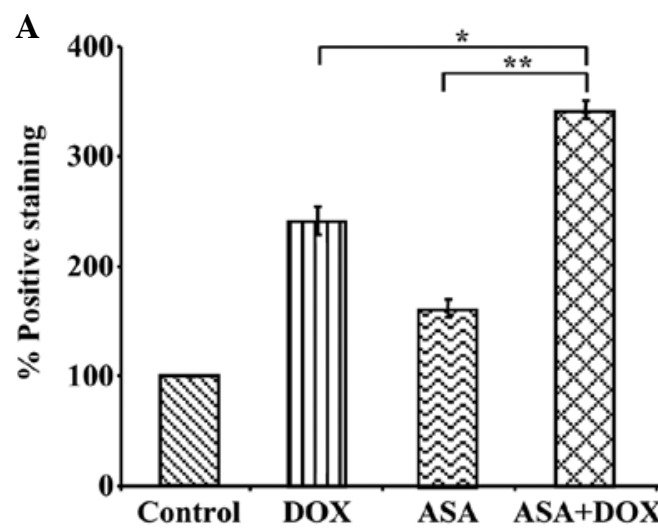

C

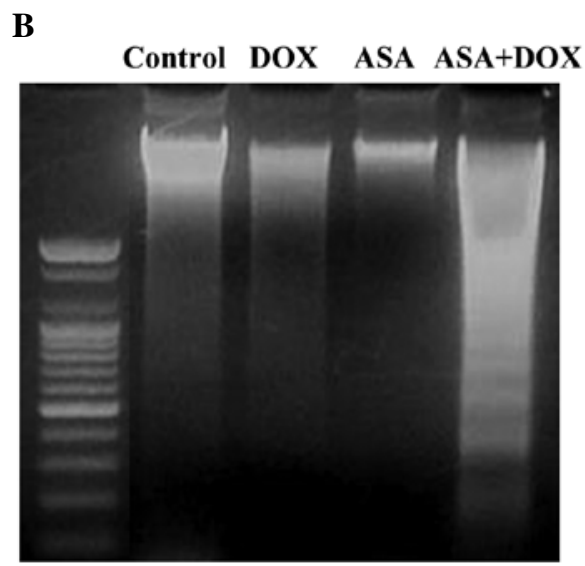

D
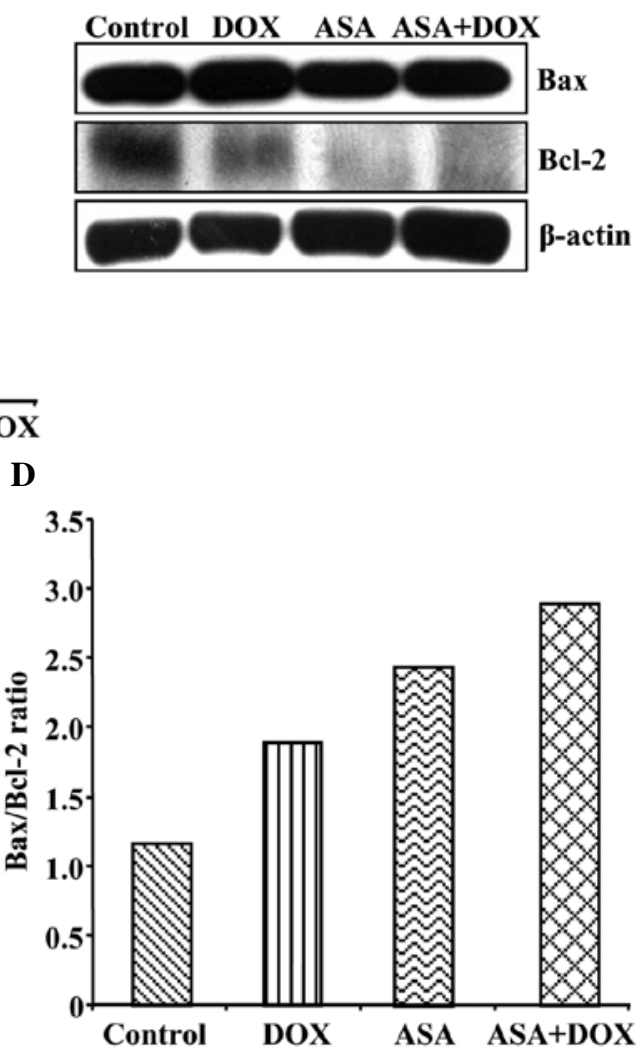

Figure 3. ASA and DOX combination showed synergism in apoptosis induction in HepG2 cells. Cells were incubated with ASA $(5 \mu \mathrm{mol} / \mathrm{ml})$ and $/$ or DOX ( $0.25 \mathrm{nmol} /$ $\mathrm{ml}$ ) for $48 \mathrm{~h}$. (A) Assessment of cell death by trypan blue staining. Statistical analyses were performed by comparison of averages between groups with ASA+DOX treatment and those DOX or ASA treatment $\left({ }^{*} \mathrm{p}<0.05 ;{ }^{* *} \mathrm{p}<0.01\right)$. (B) DNA fragmentation was detected by $1.5 \%$ agarose gel containing EtBr. A representative blot is shown from three independent experiments. (C) Effects on Bax and Bcl-2 protein levels. Protein samples ( $40 \mu \mathrm{g} / \mathrm{lane}$ ) resolved on SDS-PAGE was probed with corresponding antibodies. Actin was used as an internal control. A representative blot is shown from three independent experiments. (D) Bax/Bcl-2 ratio increased when treated in combination.

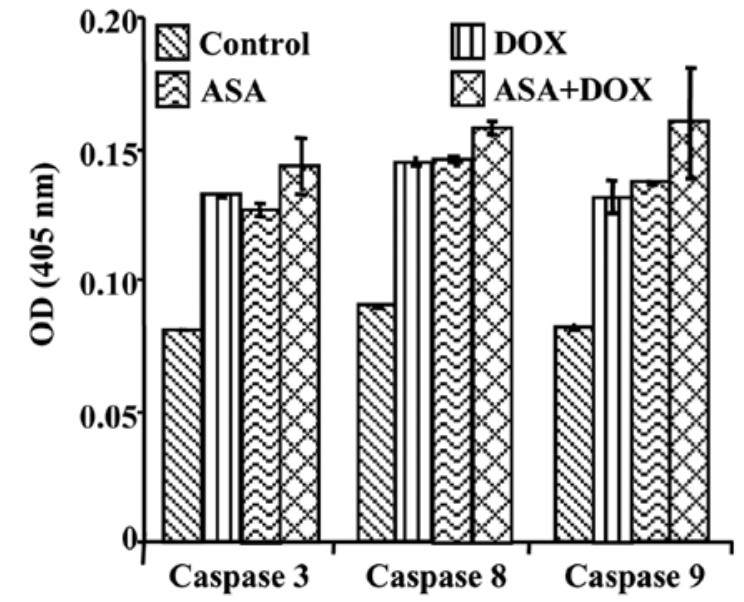

Figure 4. ASA shows synergism on augmentation of DOX-induced caspase activities. Cells were treaded with ASA $(5 \mu \mathrm{mol} / \mathrm{ml})$ and/or DOX $(0.25 \mathrm{nmol} /$ $\mathrm{ml}$ ) for $48 \mathrm{~h}$ and then levels of caspase activities were measured. Data are expressed as mean $\pm \mathrm{SEM}$ of three independent experiments.

apoptosis were investigated. As shown in Fig. 4, caspase-3, -8 and -9 were all activated by a single agent of either ASA or DOX, however, combination of these two increased the activities of these caspases higher than those with a single agent. These results indicate that induction of apoptosis by the combined treatment with ASA and DOX in HepG2 cells is at least in part, through a caspase-dependent pathway.

ASA promotes DOX-induced G2/M arrest. ASA and DOX have been reported to trigger G0/G1 (8) and G2/M (3) arrest in HepG2 cells respectively. We examined the effect of combination of ASA and DOX on cell cycle. After cells were treated with drugs for $48 \mathrm{~h}$, the combination of two drugs resulted in enhanced block in G2/M phase (Fig. 5).

ASA in combination with low-dose DOX results in tumor growth inhibition of HepG2 cell xenografts. Our in vitro observation suggests a potential role of ASA in enhancing DOX effect in the treatment of liver cancer. We examined the synergistic ability of ASA in combination with DOX to inhibit tumor growth of HepG2 cells in a nude mouse xenograft model. After 2 weeks, mice were treated with DOX at $1.2 \mathrm{mg} / \mathrm{kg} /$ dose twice a week intraperitoneally and/or ASA at $100 \mathrm{mg} / \mathrm{kg} / \mathrm{dose}$ each day orally for the entire 3-week experimental period. Mice were sacrificed and the tumors were collected (Fig. 6). Images of tumor before and after necropsy showed that the combination treatment resulted in shrinkage of tumor size compared with a single agent or control (Fig. 7A). Even though treatment with low dose DOX or ASA alone induced the inhibition of tumor growth in HepG2 
A

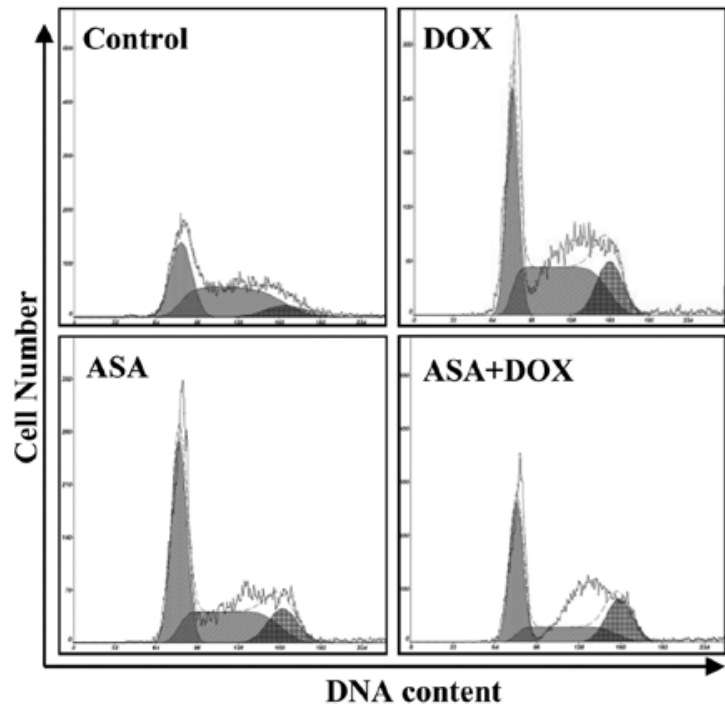

B

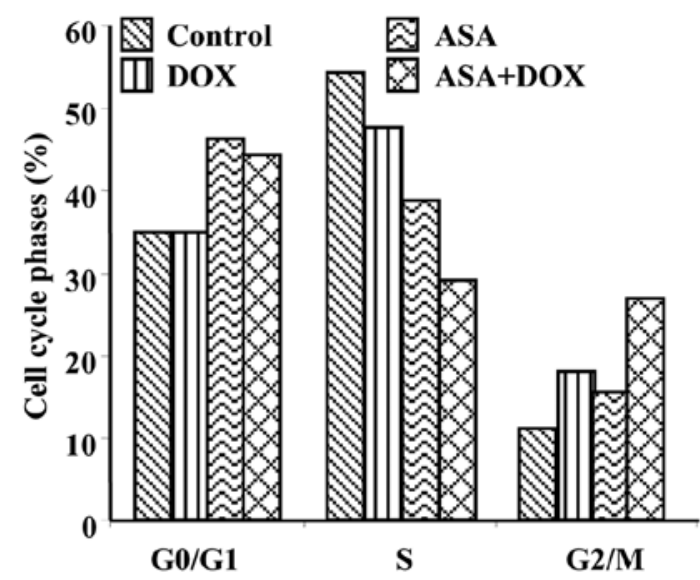

Figure 5. ASA shows synergism on DOX-induced G2/M phase arrest of the cell cycle. The cells were treated with ASA $(5 \mu \mathrm{mol} / \mathrm{ml})$ and $/ \mathrm{or} \mathrm{DOX}(0.25 \mathrm{nmol} / \mathrm{ml})$ for $48 \mathrm{~h}$. (A) Cell cycle distribution was analyzed by flow cytometry. Data are shown as one representative of at least three independent experiments. (B) Percentages of cells in each cell cycle phases are shown.

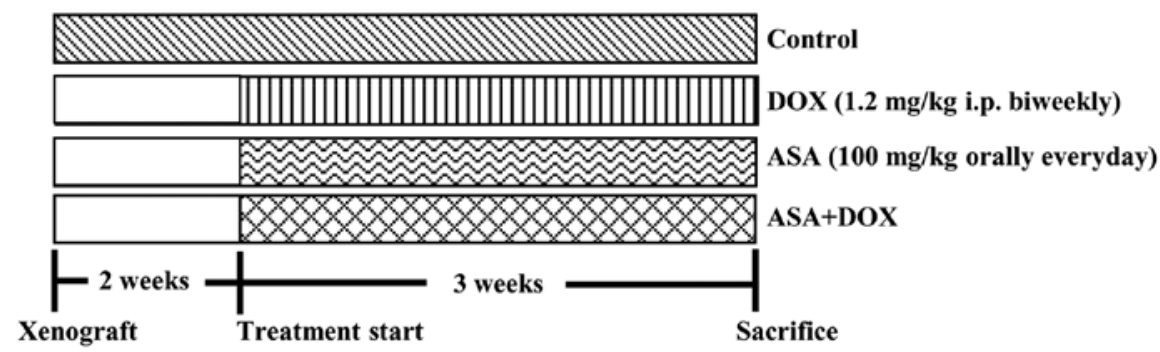

Figure 6. Experimental protocol. The mice were divided into three experimental and control groups. Nude mice at 6 weeks of age were injected s.c. with $1 \times 10^{7}$ HepG2 cells. After 2 weeks, mice were treated with DOX at $1.2 \mathrm{mg} / \mathrm{kg} / \mathrm{dose}$ twice a week intraperitoneally and ASA at $100 \mathrm{mg} / \mathrm{kg} / \mathrm{dose}$ each day orally for the entire 3-week experimental period.
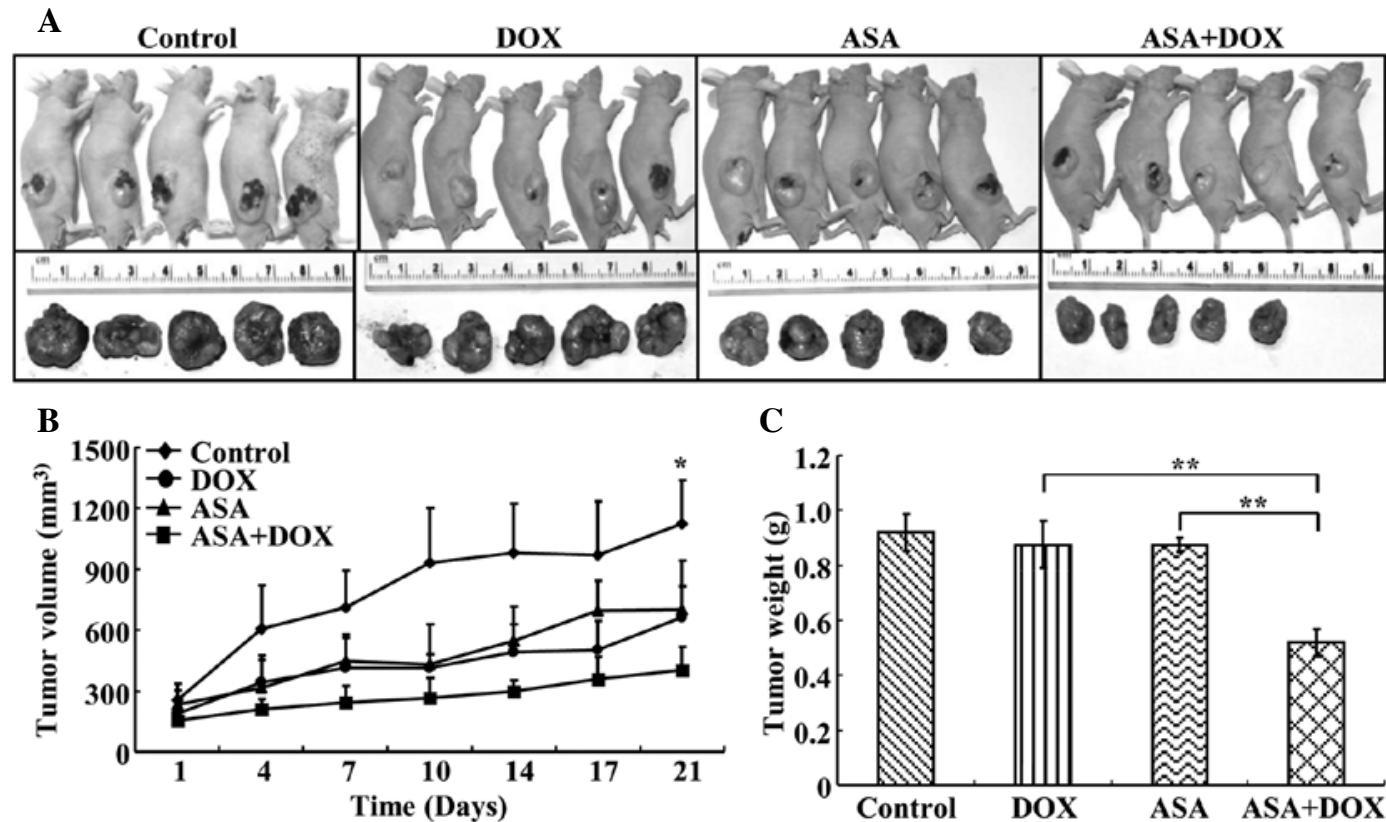

Figure 7. ASA and DOX combination inhibits growth of HepG2 cell xenografts in nude mice. (A) Image of tumors before and after necropsy is shown below the respective group. (B) Tumor growth curve. The volume of each tumor was measured twice a week after 2 weeks The average tumor volume of control mice and treated with ASA and/or DOX is plotted. (C) Final tumor weight at 5 weeks. Statistical analyses were performed by comparison of averages between groups with ASA+DOX treatment and those of DOX or ASA treatment $\left(" \mathrm{p}<0.05 ;{ }^{* *} \mathrm{p}<0.01\right)$. 
cell xenografts, combined treatment exerted more significant inhibitory effect (Fig. 7B). In addition, a considerable reduction in tumor weight was observed in the combination treatment group compared with a single agent treatment, with statistical significance (Fig. 7C). The average body weight of control or experimental mice did not vary significantly throughout the experiment (data not shown). There were no observable signs of distress in treated animals compared with control. Especially, the stomachs of aspirin-treated animals showed no observable signs of distress at the mucosal epithelial cell layers after histological examinations (data not shown). These results indicate that ASA synergizes with DOX to reduce the growth of HepG2 cell xenografts in nude mice without causing any observable side effects.

\section{Discussion}

Conventional chemotherapeutic drugs cause systemic toxicity, which is usually increased in a dose-dependent manner. This major drawback of chemotherapeutic agents has led to a new challenge in the field of cancer research and extensive study has been directed towards increasing drug activity while reducing systemic toxicity in treating cancer. In this regard, combination chemotherapy has received much attention in the search for compounds that could increase the therapeutic index of clinical anticancer drugs (17).

Previous studies showed that ASA displayed antineoplastic ability in various types of cancer cells. ASA has shown promise to be a good candidate for chemotherapy because of its selective cytotoxicity and weak mutagenicity (18). The anticancer activity of ASA is thought to be linked to its ability to inhibit cell proliferation and to induce apoptosis (19). However, NSAIDs cannot be used as a single anticancer agent because of their weak activity and are likely to be more useful in combination with other agents. We have demonstrated a synergistic relation between ASA and DOX in regard to both the inhibition of cell growth and induction of apoptosis in human hepatocellular carcinoma cells. Synergy was quantified using the CI equation of Chou and Talalay, which allows for the evaluation of two or more chemotherapeutic agents at different concentrations and effect levels (15). This methodology analyzes synergy versus antagonism of the combination, as well as their maximal anti-tumor efficacy. The results showed that ASA $(5 \mu \mathrm{mol} / \mathrm{ml})$ and DOX $(0.25 \mathrm{nmol} / \mathrm{ml})$ when used in combination could provide an enhanced anticancer effect in HepG2 cells through the growth inhibition and the induction of apoptosis in tumor cells (Figs. 1 and 2).

Apoptosis (programmed cell death) is an essential physiological process that plays a critical role in development and tissue homeostasis. However, apoptosis is also involved in a wide range of pathological conditions. Defects in apoptosis are a common event in oncogenesis and contribute to drug resistance (20). It is therefore necessary to search for ways to facilitate this apoptotic process by the use of chemotherapeutic drugs. Many studies have demonstrated that ASA was able to induce apoptosis in vitro and in vivo $(8,9,21-24)$. To investigate the apoptosis-inducing effect of ASA as a single agent and as the combination with DOX in hepatoma cells, death rate of cells was examined. Cells treated with drugs showed more prominent cell death in the combination group (Fig. 3A). DNA fragmentation method is highly specific for observing apoptotic cell death. We found that ASA or DOX alone caused no significant increase in apoptosis and is very similar to control whereas the response to the combination was more robust. So ASA and DOX worked cooperatively to commit apoptosis in the cells (Fig. 3B). The synergy between DOX and ASA might have been due to the involvement of Bcl-2 modulation when DOX and ASA were combined. Drug-induced apoptosis in several types of malignant tumor cells, mediated through various pathways, could be strongly inhibited by Bcl-2 (25). Bcl-2 family is a set of cytoplasmic protein members that regulate apoptosis. The two main groups of this family, Bcl-2 and Bax proteins, are functionally opposed: Bcl-2 acts to inhibit apoptosis, whereas Bax counteracts this effect. The current findings showed that ASA and/or DOX decreased the expression of Bcl-2; however, there were no change in Bax expression level (Fig. 3C). Furthermore, a significant increase in the ratio of Bax/Bcl-2 was observed when ASA was treated in combination with DOX, which was correlated with the incidence of apoptosis (Fig. 3D).

The process of apoptosis involves complex biochemical events that are carried out by a family of cysteine proteases called caspases. In the present study, we found that caspase activities, including caspase- $3,-8$, and -9 , were increased when ASA was combined with DOX (Fig. 4). Therefore, the apoptosis induced by the combination of ASA and DOX seem to be caspasedependent and to involve both the extrinsic and intrinsic parts of the caspase cascade.

Cells duplicate through a process known as the cell cycle, one of the most fundamental procedures of living organisms, allowing the organisms to reproduce themselves. Cell cycle is regulated by a wide variety of external factors that act through an intracellular signal transduction network, and thereby leading to the progression of cell cycle or otherwise to the cell cycle arrest or cell death. ASA has been reported to block in G0/G1 phase of cell cycle (8) and DOX in G2/M phase (3) in HCC cells. Combination of ASA and DOX synergistically blocked cell cycle in G2/M-phases (Fig. 5).

Various anticancer agents, including DOX, induce oxidative stress, an action indispensable for their anticancer activity. Reactive oxygen species (ROS) generation may also be crucial for ASA-mediated apoptosis (8). So we studied intracellular ROS generation and our findings showed that ASA or DOX alone induced ROS but when combined each other, induced a higher percentage of ROS (data not shown).

Importantly, we report that administration of ASA and DOX caused a considerable reduction in the growth and weight of HepG2 cell xenograft tumors in nude mice compared to the control or a single drug (Fig. 7). There was no morbidity due to treatment, nor was there drastic variation in activity level or significant weight loss/gain between control and treated animals indicating low toxicity of ASA in vivo (data not shown).

It has been reported that ASA is used to exert anticancer effects through the inhibition of cell cycle progression, induction of apoptosis, and inhibition of angiogenesis (8). The exact mechanisms, however, are not clearly elucidated yet. It has been postulated that COX-independent mechanisms as well as COX-dependent pathway were involved.

The concentration of ASA used in our in vivo study (100 mg/ $\mathrm{kg} /$ day) is equivalent to a clinical dose of $520 \mathrm{mg}$ for average body surface area or approximately one ASA tablet taken for 
analgesic purpose (24). We observed anticancer effect of ASA in vivo at this low dose, however, the proper dose of ASA needed to see the beneficial anticancer effect in human should be determined through clinical investigation.

ASA, being one of the most widely used anti-inflammatory drug, is currently recommended in a daily dose for the prevention of cardiovascular disease. Our present findings have important clinical implications in that synergistic anticancer effect of combination of ASA and DOX could allow DOX to be used at a lowered dose for the treatment of cancer, consequently minimizing its dose-related side effects. Although NSAIDs are long established and commonly used medications, their use as combination partners of classical anticancer agents is very new and promising. Further clinical investigations are warranted to provide evidence on the efficacy in human, proper dose, and long-term side effects of the combination.

\section{Acknowledgements}

This work was supported by the Bio-Scientific Research Grant funded by the Pusan National University (PNU, Bio-Scientific Research Grant) (PNU-2008-101-20080598000). We thank Aging Tissue Bank for providing research information. Mohammad Akbar Hossain is the recipient of the Korea Research Foundation Grant funded by the Korea Government (MOEHRD) (KRF-2006-2-E00029).

\section{References}

1. GLOBOCAN 2008: Cancer fact sheet. http://globocan.iarc.fr/ factsheets/cancers.

2. Dudeck O and Ricke J: Advances in regional chemotherapy of the liver. Expert Opin Drug Deliv 8: 1057-1069, 2011.

3. Cheng J, Haimin L, Young H, Min H, Ling B, Yunxin C, Wenjie S and Kefeng D: Combination chemotherapy of doxorubicin and paclitaxel for hepatocellular carcinoma in vitro and in vivo. $\mathrm{J}$ Cancer Res Clin Oncol 136: 267-274, 2010.

4. Gwyn K and Sinicrope FA: Chemoprevention of colorectal cancer. Am J Gastroenterol 97: 13-21, 2002.

5. Baron JA and Sandler RS: Nonsteroidal anti-inflammatory drugs and cancer prevention. Annu Rev Med 51: 511-523, 2000.

6. Flossmann E and Rothwell PM: Effect of aspirin on long-term risk of colorectal cancer: consistent evidence from randomised and observational studies. Lancet 369: 1603-1613, 2007.

7. Yan KH, Yao CJ, Chang HY, Lai GM, Cheng AL and Chuang SE: The synergistic anticancer effect of troglitazone combined with aspirin causes cell cycle arrest and apoptosis in human lung cancer cells. Mol Carcinog 49: 235-246, 2010.

8. Reza H, Johan A and Benedict S: Acetylsalicylic acid-induced oxidative stress, cell cycle arrest, apoptosis and mitochondrial dysfunction in human hepatoma HepG2 cells. Eur J Pharmacol 668: 15-24, 2011.

9. Hossain MA, Kim DH, Jang JY, Kang YJ, Yoon JH, Moon JO, Chung HY, Kim GY, Choi YH, Copple BL and Kim ND: Aspirin induces apoptosis in vitro and inhibits tumor growth of human hepatocellular carcinoma cells in a nude mouse xenograft model. Int J Oncol 40: 1298-1304, 2012.

10. Xiang S, Sun Z, He Q, Yan F, Wang Y and Zhang J: Aspirin inhibits ErbB2 to induce apoptosis in cervical cancer cells. Med Oncol 27: 379-387, 2010.
11. Lee JH, Park SE, Hossain MA, Kim MY, Kim MN, Chung HY, Choi JS, Yoo YH and Kim ND: 2,3,6-Tribromo-4,5dihydroxybenzyl methyl ether induces growth inhibition and apoptosis in MCF-7 human breast cancer cells. Arch Pharm Res 30: 1132-1137, 2007.

12. Park SE, Park C, Kim SH, Hossain MA, Kim MY, Chung HY, Son WS, Kim GY, Choi YH and Kim ND: Korean red ginseng extract induces apoptosis and decreases telomerase activity in human leukemia cells. J Ethnopharmacol 121: 304-312, 2009

13. Park SE, Lee SW, Hossain MA, Kim MY, Kim MN, Ahn EY, Park YC, Suh HS, Kim GY, Choi YH and Kim ND: A chenodeoxycholic derivative, HS-1200, induces apoptosis and cell cycle modulation via Egr-1 gene expression control on human hepatoma cells. Cancer Lett 270: 77-86, 2008.

14. Wang S, Ren W, Liu J, Lahat G, Torres K, Lopez G, Lazar AJ, Hayes-Jordan A, Liu K, Bankson J, Hazle JD and Lev D: TRAIL and doxorubicin combination induces proapoptotic and antiangiogenic effects in soft tissue sarcoma in vivo. Clin Cancer Res 16: 2591-2604, 2010

15. Chou TC and Talalay P: Analysis of combined drug effects: a new look at a very old problem. Trends Pharmacol Sci 4: 450-454, 1983.

16. Li S, Zhou Y, Wang R, Zhang H, Dong Y and Clement IP: Selenium sensitizes MCF-7 breast cancer cells to doxorubicininduced apoptosis through modulation of phospho-Akt and its downstream substrates. Mol Cancer Ther 6: 1031-1038, 2007.

17. Abaza MSI, Bahman AMA and Attiyah RJA: Roscovitine synergizes with conventional chemo-therapeutic drugs to induce efficient apoptosis of human colorectal cancer cells. World J Gastroenterol 14: 5162-5175, 2008.

18. Kim CH, Kim MY, Moon JY, Hwang JW, Lee SY, Joo YM, Han SI, Park HG and Kang HS: Implication of NAG-1 in synergistic induction of apoptosis by combined treatment of sodium salicylate and PI3K/MEK1/2 inhibitors in A549 human lung adenocarcinoma cells. Biochem Pharmacol 75: 1751-1760, 2008.

19. Bellosillo B, Pique M, Barragan M, Castano E, Villamor N and Colomer D: Aspirin and salicylate induce apoptosis and activation of caspases in B-cell chronic lymphocytic leukemia cells. Blood 92: 1406-1414, 1998.

20. Fisher DE: Apoptosis in cancer therapy: crossing the threshold. Cell 78: 539-542, 1994.

21. Park IS, Jo JR, Hong H, Nam KY, Kim JB, Hwang SH, Choi MS, Ryu NH, Jang HJ, Lee SH, Kim CS, Kwon TG, Park GY, Park JW and Jang BC: Aspirin induces apoptosis in YD-8 human oral squamous carcinoma cells through activation of caspases, down-regulation of Mcl-1, and inactivation of ERK-1/2 and AKT. Toxicol In Vitro 24: 713-720, 2010.

22. Iglesias-Serret D, Piqué M, Barragán M, Cosialls AM, Santidrián AF, González-Gironès DM, Coll-Mulet L, De Frias M, Pons G and Gil J: Aspirin induces apoptosis in human leukemia cells independently of NF-kappaB and MAPKs through alteration of the Mcl-1/Noxa balance. Apoptosis 15: 219-229, 2010.

23. Deng L, Hu S, Baydoun AR, Chen J, Chen X and Cong X: Aspirin induces apoptosis in mesenchymal stem cells requiring Wnt/beta-catenin pathway. Cell Prolif 42: 721-730, 2009.

24. Stark LA, Reid K, Sansom OJ, Din FV, Guichard S, Mayer I, Jodrell DI, Clarke AR and Dunlop MG: Aspirin activates the NF-kappaB signalling pathway and induces apoptosis in intestinal neoplasia in two in vivo models of human colorectal cancer. Carcinogenesis 28: 968-976, 2007.

25. Bonetti A, Zaninelli M, Leone R, Cetto GL, Pelosi G, Biolo S, Menghi A, Manfrin E, Bonetti F and Piubello Q: bcl-2 but not p53 expression is associated with resistance to chemotherapy in advanced breast cancer. Clin Cancer Res 4: 2331-2336, 1998. 